\title{
A SUSTENTABILIDADE DA POLÍTICA FISCAL NA PRESENÇA DE QUEBRAS ESTRUTURAIS: UMA EVIDÊNCIA PARA O RIO GRANDE DO SUL ${ }^{1}$
}

\author{
Cristiano Aguiar de Oliveira² \\ Daniela Pias ${ }^{3}$
}

\begin{abstract}
Este artigo avalia a sustentabilidade da política fiscal do estado do Rio Grande do Sul no longo prazo. Para isso, utiliza informações do período compreendido entre 1970 e 2015, a fim de testar a existência de raízes unitárias no resultado primário e na dívida pública, bem como testar a existência de cointegração entre a dívida pública e o resultado primário e entre a receita tributária e a despesa primária, a partir de testes que permitem a presença de quebras estruturais. Diferentemente da literatura existente, os resultados deste estudo indicam que a política fiscal do estado não é sustentável no longo prazo. 0 artigo conclui que são necessárias mudanças na política fiscal, com o aumento de receitas e/ou redução de despesas, a fim de que não somente o estado tenha recursos para honrar seus compromissos no curto prazo, mas também para garantir sua solvência no longo prazo.
\end{abstract}

Palavras-chave: política fiscal; raiz unitária; cointegração; Rio Grande do Sul.

\section{THE SUSTAINABILITY OF FISCAL POLICY IN THE PRESENCE OF STRUCTURAL BREAKS: AN EVIDENCE FROM RIO GRANDE DO SUL}

This paper evaluates the sustainability of the fiscal policy of the state of Rio Grande do Sul in the long run. To this goal, it uses information from the period 1970 to 2015 to test the existence of unitary roots in primary budget balance and public debt and to test the existence of cointegration between public debt and primary budget balance and between tax revenue and primary expenditure with tests that allow the presence of structural breaks. Differently from the existing literature, the results of this study indicate that the state's fiscal policy is not sustainable in the long term. The paper concludes that changes in fiscal policy are necessary, with the increase of revenues and or reduction of expenses, not only to the state to have the resources to honor its payments in the short run, but also to guarantee its solvency in the long run.

Keywords: fiscal policy; unit roots; cointegration; Rio Grande do Sul.

\section{LA SOSTENIBILIDAD DE LA POLÍTICA FISCAL EN PRESENCIA DE QUIEBRAS ESTRUCTURALES: EVIDENCIA PARA RIO GRANDE DO SUL}

Este artículo evalúa la sostenibilidad de la política fiscal del estado de Rio Grande do Sul a largo plazo. Para este fin, utiliza información del período de 1970 a 2015 para probar la existencia de raíces unitarias en el resultado primario y en la deuda pública y para probar la existencia de cointegración entre la deuda pública y el resultado primario y entre los ingresos fiscales y el gasto primario de pruebas que permiten la presencia de quiebras estructurales. A diferencia de la literatura

1. DOl: http://dx.doi.org/10.38116/ppp54art05

2. Professor associado da Universidade Federal do Rio Grande (FURG).E-mail: <cristiano.oliveira@furg.br>.

3. Bacharel em economia pela FURG. E-mail:<danielapias@hotmail.com>. 
existente, los resultados de este estudio indican que la política fiscal del estado no es sostenible a largo plazo. El artículo concluye que los cambios en la política fiscal son necesarios, con el aumento de los ingresos y/o la reducción de los gastos, para que no solo el estado tenga recursos para cumplir sus compromisos a corto plazo, sino también para garantizar su solvencia a largo plazo.

Palabras clave: política fiscal; raíz unitaria; cointegración; Rio Grande do Sul.

\section{LA DURABILITE DE LA POLITIQUE BUDGETAIRE EN PRESENCE DE RUPTURES STRUCTURELLES: DES PREUVES POUR RIO GRANDE DO SUL}

Cet article évalue la durabilité de la politique budgétaire de l'État de Rio Grande do Sul à long terme. À cette fin, il utilise des informations de la période 1970 à 2015 pour tester l'existence de racines unitaires dans le résultat primaire et dans la dette publique et pour tester l'existence d'une cointégration entre la dette publique et le résultat primaire et entre les recettes fiscales et les dépenses primaires des tests qui permettent la présence de ruptures structurelles. Contrairement à la littérature existante, les résultats de cette étude indiquent que la politique budgétaire de l'État n'est pas viable à long terme. L'article conclut que des changements dans la politique budgétaire sont nécessaires, avec l'augmentation des revenus et la réduction des dépenses, afin que non seulement l'État dispose de ressources pour honorer ses engagements à court terme, mais aussi pour garantir sa solvabilité dans le long terme.

Mots-clés: politique fiscale; racine unitaire; cointegration; Rio Grande do Sul.

JEL: C2; E62; H72; H74.

\section{INTRODUÇÃO}

A sustentabilidade das dívidas públicas e das políticas fiscais das Unidades da Federação brasileira (UFs) é um tema que ganhou importância com a estabilização dos preços ocorrida com o Plano Real. O fim do financiamento público por meio de senhoriagem expôs os problemas fiscais das UFs, elevados deficit primários, assim como alta dívida pública.

Todavia, a partir de 1999, começa a haver uma mudança de postura fiscal, com a promulgação da Lei de Responsabilidade Fiscal (LRF) em 2000, trazendo consigo um conjunto de normas e limites para o controle das finanças públicas. Nesse período, por exemplo, a Resolução do Senado Federal no 40/2001 estabeleceu o limite de endividamento de $200 \%$ da receita corrente líquida, que é a receita da UF, como tributos, menos as transferências feitas para os municípios.

O Rio Grande do Sul é a única UF que ainda ultrapassa o limite de endividamento de $200 \%$ da receita corrente líquida. O estado enfrenta dificuldades não só para honrar o serviço (pagamento de juros mais amortizaçóes) de sua dívida, mas também para honrar as suas despesas correntes, tais como o pagamento de servidores e fornecedores. Entretanto, deve-se deixar claro que estes problemas, embora agravados recentemente, não são novos. Por exemplo, entre 1996 e 1999, o estado não se tornou inadimplente porque houve diversas privatizaçóes no período. 
Desde então, apesar de alguns pequenos períodos de ajuste nas contas públicas em grande parte devido ao aumento de receitas associado ao crescimento da economia e ao aumento da carga tributária, assim como ao uso de depósitos judiciais como fonte de financiamento, mas nunca em decorrência de reduçâo de despesas -, o Rio Grande do Sul chegou à situação atual, que pode ser classificada como falimentar. Para Marques Junior (2013), a atual situação do estado é de crise financeira acompanhada de um forte endividamento, com deficit público e dívida crescente, e com parcelamento de salários dos servidores e atrasos nos pagamentos de fornecedores.

Neste contexto adverso de curto prazo, de crise econômica e fiscal que persiste pelo menos desde 2014, no Brasil e no estado do Rio Grande do Sul, a sustentabilidade da política fiscal passa a ser novamente questionada, uma vez que a escassa literatura existente conclui que, apesar dos problemas de curto prazo, a política fiscal do Rio Grande do Sul é sustentável no longo prazo. Estes são os casos dos estudos de Marques Junior (2005), Marques Junior e Jacinto (2006) e Oliveira e Marques Junior (2011), os quais utilizam as metodologias propostas pela literatura internacional para definição do que vem a ser uma política fiscal sustentável.

Para Hamilton e Flavin (1986), Wilcox (1989) e Trehan e Walsh (1991), a política fiscal é sustentável se o resultado primário e a dívida pública são séries estacionárias. No entanto, segundo Oliveira e Marques Junior (2011), tal condição é demasiadamente rígida, pois as variáveis econômicas, em geral, não apresentam tal comportamento. Assim, Hakkio e Rush (1991) e Tanner e Liu (1994) argumentam que a política fiscal pode ser sustentável mesmo quando as referidas variáveis não são estacionárias. Neste caso, seria suficiente a existência de uma combinação linear, entre as variáveis, que seja estacionária no longo prazo, ou seja, bastaria existir a cointegração entre as séries para se satisfazer a condição de sustentabilidade. Isto ocorreria, por exemplo, quando a receita e a despesa total fossem cointegradas.

Seguindo essas metodologias, Marques Junior (2005) avaliou a sustentabilidade da política fiscal para o estado do Rio Grande do Sul no período de 1970 a 1997. O autor testou a estacionariedade para a dívida mobiliária, que é a dívida contratada por intermédio da emissão de títulos públicos, deficit primário, e deficit público em relaçáo ao produto interno bruto (PIB), concluindo que a política fiscal foi sustentável naquele período. Em continuidade ao seu trabalho, Marques Junior e Jacinto (2006) estudaram a sustentabilidade da política fiscal para o estado do Rio Grande do Sul por meio da cointegração entre receita tributária e despesa total, tendo sido a análise feita em dois períodos - 1970 a 1997 e 1970 a 2003. Oliveira e Marques Junior (2011) completam os estudos para o estado, ao avaliarem a sustentabilidade da política fiscal utilizando um modelo de correção de equilíbrio com mudança markoviana de regime, no período entre 1970 e 2007. Todos os estudos referidos sugerem que a política fiscal, apesar dos problemas apresentados no curto prazo, é sustentável no longo prazo. 
Todavia, o último trabalho mencionado sobre o tema tem sua base de dados se encerrando no ano de 2007 , e, desde então, houve uma aparente deterioração nas contas públicas que justifica uma revisita ao tema, com informaçóes mais atualizadas. Por exemplo, as despesas com pessoal (ativos e inativos) do estado cresceram cerca de $40 \%$ em termos reais entre 2009 e 2015. Ademais, os testes empregados anteriormente para avaliar a sustentabilidade da política fiscal gaúcha ou potencialmente apresentam viés, devido à presença de quebras estruturais, ou apresentam baixo poder, devido às suas suposiçôes. Nesse sentido, este estudo visa avaliar a sustentabilidade da política fiscal do Rio Grande do Sul com um período mais longo que os estudos anteriores, de 1970 a 2015, e, além dos métodos tradicionais, utiliza novos métodos, entre os quais os testes de raiz unitária com quebras estruturais, propostos por Lee e Strazicich (2003), e o teste de cointegração com quebras estruturais de Gregory e Hansen (1996).

O artigo está organizado da seguinte maneira: além desta introdução, há mais quatro seçôes. A próxima seção apresenta a dinâmica das finanças públicas e a sua relação com sustentabilidade da política fiscal no longo prazo, ou seja, consta de fundamentação teórica que servirá de base para os testes realizados sobre o cumprimento da restrição orçamentária intertemporal do governo. Na terceira seção, é apresentada a metodologia econométrica e a base de dados utilizada, enquanto a quarta seção traz os resultados dos testes e sua análise. Por fim, a última seção resume as principais conclusóes do estudo.

\section{A RESTRIÇÃO ORÇAMENTÁRIA INTERTEMPORAL}

A exemplo do que ocorre com as famílias, o governo possui uma restrição orçamentária a ser respeitada. É por intermédio da combinação entre despesas públicas e receita tributária que se avalia a sustentabilidade de uma determinada política fiscal. O governo até pode temporariamente ter mais despesas do que receitas e gerar endividamento. No entanto, cabe salientar que a opção pelo endividamento está condicionada à sua capacidade de obter crédito, que, por sua vez, está ligada à credibilidade do governo; ou seja, a sua capacidade de endividamento depende das expectativas dos agentes quanto à sustentabilidade de sua política fiscal.

Um governo estadual no Brasil tem a seguinte restrição orçamentária:

$$
\mathrm{B}_{\mathrm{t}}-\mathrm{B}_{\mathrm{t}-1}=\mathrm{rB}_{\mathrm{t}-1}+\mathrm{G}_{\mathrm{t}}-\mathrm{T}_{\mathrm{t}}
$$

Onde $B_{t}$ é o estoque de dívida pública, $r$ é a taxa de juros paga sobre a dívida, $G_{t}$ é o gasto primário e $T_{t}$ é a receita tributária. Esta equação mostra que a dívida pública cresce com o pagamento de juros sobre a dívida (dado por $r B_{t-1}$ ) e com a geração de deficit primários (dados por $G_{t}-T_{t}$ ). Note-se que a restrição orçamentária do governo não admite a coleta de senhoriagem, uma vez que os estados brasileiros não podem emitir moeda e nem títulos públicos. Rearranjando os termos da equação (1) e dividindo pelo produto real $Y_{t}$, tem-se que: 


$$
\begin{aligned}
& B_{t}=(1+r) B_{t-1}+G_{t}-T_{t} \\
& \frac{B_{t}}{Y_{t}}=(1+r) \frac{B_{t-1}}{Y_{t}}+\frac{G_{t}-T_{t}}{Y_{t}}
\end{aligned}
$$

Considerando-se que $\frac{\mathrm{Y}_{\mathrm{t}-1}}{\mathrm{Y}_{\mathrm{t}}}=\frac{1}{\left(1+\mathrm{Y}_{\mathrm{t}}\right)}$, onde $\gamma_{t}$, mantida constante, é a taxa de crescimento do produto real, e substituindo $g_{t}-\tau_{t}$ por $d_{t}$, obtém-se:

$$
b_{t}=\frac{(1+r)}{\left(1+\gamma_{t}\right)} b_{t-1}+d_{t}
$$

Assim como em Oliveira e Marques Junior (2011), considera-se que $\frac{(1+\mathrm{r})}{\left(1+\gamma_{t}\right)}=(1+\rho)$, onde $\rho$ representa a taxa de juros real descontada da taxa de crescimento do produto. Para simplificar, assume-se que $\rho$ é constante e positiva. Solucionando-se a equação (3), e supondo-se que $t$ tende ao infinito, tem-se:

$$
\mathrm{b}_{0}=(1+\rho) \mathrm{b}_{\mathrm{t}-1}=\sum_{\mathrm{i}=0}^{\infty} \frac{\mathrm{d}_{\mathrm{t}-1}}{(1+\rho)}+\lim _{\mathrm{i} \rightarrow \infty} \frac{\mathrm{b}_{\mathrm{t}+\mathrm{i}}}{(1+\rho)}
$$

Logo, para que a restrição orçamentária intertemporal seja respeitada e a política fiscal seja sustentável, é preciso que o último termo da equação (4) seja igual a zero, isto é:

$$
\lim _{i \rightarrow \infty} \frac{b_{t+i}}{(1+\rho)^{i}}=0
$$

Esta condição, conhecida como no Ponzi game, estabelece que o governo não pode se endividar infinitamente. Assim, para que a política fiscal seja considerada sustentável no longo prazo, é preciso que:

$$
\mathrm{b}_{0}=\sum_{\mathrm{i}=0}^{\infty} \frac{\mathrm{d}_{\mathrm{t}-1}}{(1+\rho)^{i}}
$$

Ou seja, a razão dívida pública/PIB deverá ser igual ao valor presente dos superavit primários corrente e futuros em determinado ponto do tempo. Isto ocorre quando a dívida pública e os superavit primários forem estacionários (Hamilton e Flavin, 1986; Wilcox, 1989; Trehan e Walsh, 1991) ou quando a dívida pública e os resultados primários não forem estacionários, mas cointegrados. Neste caso, quando a regressão entre a receita e a despesa primária tem coeficiente igual a 1 , tem-se sustentabilidade forte, e quando o coeficiente é menor do que 1, ou seja, as receitas crescem menos do que as despesas, tem-se sustentabilidade fraca (Hakkio e Rush, 1991; Tanner e Liu, 1994). Essas definições de sustentabilidade da política fiscal, amplamente utilizadas pela literatura recente (Curtasu, 2011; Afonso e Jales, 2012; Ndoricimpa, 2013; Camarero, Carrion-I-Silvestre e Tamarit, 2015, entre outros), serão avaliadas neste estudo. 


\section{METODOLOGIA E DADOS}

\subsection{Metodologia}

Economistas possuem o interesse em saber como séries macroeconômicas reagem a choques. Esta reação pode ser bastante distinta, conforme as características da série em questão. Se estas séries são estacionárias, choques possuem efeitos transitórios; e se estas são não estacionárias, choques possuem efeitos permanentes. Além disso, séries estacionárias possuem a característica de reverter para sua média ou sua tendência, o que permite seu uso em modelos lineares de regressão e em previsóes. No entanto, existem duas formas de estacionariedade. A estacionariedade é dita forte quando um processo estocástico ou uma série temporal apresentam uma função de densidade de probabilidade conjunta invariante no tempo. Contudo, essa é uma condição muito restritiva e quase não se verifica na prática. Por isso, ao invés de supor que toda a distribuição é invariante no tempo, estabelecem-se restriçốes para a média, a variância e a covariância, a fim de se ter um conceito menos restritivo, chamado de estacionariedade fraca. Esta ocorre quando, simultaneamente: $i$ ) o segundo momento não centrado for finito, ainda que desigual em diferentes períodos $\left(E\left|y_{t}\right|^{2}<\infty\right)$; ii) a média for igual para todos os períodos $\left(E\left(y_{t}\right)=\mu\right.$, para todo $\left.t \in \mathbb{Z}\right)$; iii) a variância for igual para todo o período; e $i v$ ) a autocovariância não depender do tempo, embora possa depender da distância temporal entre as observaçóes $\left(E\left(y_{t}-\mu\right)\left(y_{t-j}-\mu\right)=\gamma_{j}\right)$. Por sua vez, séries não estacionárias possuem raízes unitárias e, consequentemente, médias e variâncias variantes no tempo.

Logo, um caminho natural para se avaliar a estacionariedade das séries é testar a presença de raiz unitária. Os testes mais tradicionais são os testes de Dickey-Fuller aumentado e o de Phillips-Perron. Suponhamos um modelo autorregressivo de primeira ordem $-\mathrm{AR}(1)$ - que pode ser reescrito com o operador de defasagens:

$$
\begin{gathered}
y_{t}=\phi_{1} y_{t-1}+\varepsilon_{t} \\
\left(1-\phi_{1} L\right) y_{t}=\varepsilon_{t}
\end{gathered}
$$

Ao se igualar a equação entre parênteses a zero, tem-se um polinômio característico $1-\phi_{1} L=0$, em que, resolvendo para $L$, tem-se $L=\frac{1}{\phi_{1}}$. Assim:

- $\quad$ se $\phi_{1}=1$, a solução é $L=1$, e temos então a raiz igual a 1 , chamada raiz unitária. $\mathrm{O}$ modelo torna-se um passeio aleatório puro $y_{t}=y_{t-1}+\varepsilon_{t}$, ou seja, é não estacionário;

- $\quad$ se $\left|\phi_{1}\right|<1$, a solução é $|L|>1$, e a série não é um passeio aleatório, e sim um processo estacionário; e

- $\left|\phi_{1}\right|>1$, a solução é $|L|<1$, e a série é denominada explosiva, não estacionária. 
Essa é a intuição básica do teste proposto por Dickey-Fuller (1979). Todavia, cabe ressaltar que, quando a série é representada por um AR de ordem maior que 1 , ou se os resíduos forem correlacionados, isto viola as suposiçóes do teste originalmente proposto pelos autores. Por essa razão, utiliza-se uma versão modificada para suplantar esses problemas: o teste de Dickey-Fuller aumentado (ADF). Este é semelhante ao teste Dickey-Fuller (DF), contudo, inclui termos de diferenças defasadas suficientes para retirar a autocorrelação dos resíduos.

Assim, estima-se a seguinte equação:

$\Delta y_{t}=\alpha_{0}+\alpha_{1} t+\gamma y_{t-1}+\sum_{i=1}^{m} \alpha_{i} \Delta y_{t-1}+\varepsilon_{t}$

Em que $\alpha_{0}$ é o intercepto, $t$ é a tendência, $\Delta$ é o operador diferença $\left(\Delta y_{t}=y_{t}-y_{t-1}\right)$ e $e_{t}$ é o erro. $\mathrm{O}$ teste de raiz unitária testa a hipótese nula de presença de raiz unitária $\left(H_{0}: \phi=1 \leftrightarrow H_{0}: \gamma=0\right)$ contra a hipótese alternativa de que a série é estacionária $\left(H_{1}: \phi<1 \leftrightarrow H_{1}: \gamma<0\right)$. Logo, o teste ADF consiste na estimação da equação (8) por mínimos quadrados ordinários (MQO) e no teste da significância estatística de $\gamma$. Entretanto, o teste de hipótese a respeito de $\gamma$ não segue a distribuição $t$ de Student convencional, por se tratar de um possível passeio aleatório; desse modo, utiliza-se a distribuição $\tau$, tabulada por Dickey e Fuller (1979) com base em simulaçōes de Monte Carlo.

Os testes $\mathrm{DF}$ e $\mathrm{ADF}$ são conhecidos por terem um baixo poder estatístico, pois apresentam uma alta probabilidade de se cometer o erro tipo 2, aceitar $H_{0}$ quando ela é falsa, ou seja, assumir que as séries não são estacionárias quando, na verdade, são. Nesse sentido, Phillips e Perron (1988) propóem uma correção não paramétrica no teste de Dickey e Fuller, permitindo que este seja consistente mesmo quando há variáveis defasadas dependentes e os erros são correlacionados. Os autores também definem testes diretamente sobre os coeficientes do modelo e, ao invés de utilizarem a estatística $t$, sugerem o uso de testes de $z_{\alpha}$, para enfatizar que se trata de testes sobre a distribuição do coeficiente, e, assim, comparam os resultados com os testes baseados na distribuição da estatística $t$, ambos com a hipótese nula de raiz unitária.

Fazendo essas correções para lidar com o problema de autocorrelação nos resíduos, esses testes funcionam bem (têm alto poder) na ausência de quebras estruturais nas séries. No entanto, tal como argumenta Perron (1989), tais testes são viesados, pela omissão de variáveis relevantes, e costumam não rejeitar a hipótese nula na presença de quebras estruturais. $\mathrm{O}$ autor enfatiza que muitas séries macroeconômicas estão sujeitas a choques infrequentes de grande magnitude, que levam a aceitar a hipótese nula de presença de raiz unitária, enquanto, na verdade, estas revertem para sua média diante de choques frequentes de pequena magnitude. Propóe então uma extensão do teste $\mathrm{ADF}$ que permite incluir uma quebra estrutural conhecida. Uma característica importante deste teste é que ele permite a presença 
de quebras estruturais tanto na hipótese nula quanto na hipótese alternativa - o que, como será visto em seguida, é importante para garantir a consistência dos testes de raiz unitária. A principal crítica ao procedimento proposto por Perron (1989) é que a inclusão de quebras estruturais exógenas permite uma espécie de datamining, ou seja, dá poder ao pesquisador de escolher o período para a quebra estrutural conforme o seu interesse em aceitar ou rejeitar a hipótese nula de presença de raiz unitária. Assim, o mais correto seria determinar o período de forma endógena.

Perron e Vogelsang (1992) e Perron (1997) sugerem um teste que apresenta diferentes alternativas para modelar quebras estruturais, a saber: $i$ ) Outlier Aditivo (OA), que seria capaz de capturar mudanças abruptas; e ii) Outlier Inovacional (OI), que seria capaz de capturar mudanças graduais na série. Ademais, baseiam seu teste no menor valor para o teste $t$ na soma de todos os coeficientes autorregressivos sobre todas as possíveis quebras estruturais na série. Isto permite, por exemplo, evitar o viés de aceitação da hipótese nula, pois se busca o modelo com maior chance de rejeição. Se, mesmo após este procedimento, ainda se aceitar a hipótese nula, este é um forte sinal de que realmente a série é nâo estacionária mesmo na presença de quebras estruturais.

Apesar desses avanços, alguns autores questionam o uso de somente uma quebra estrutural nos testes de raiz unitária. Por exemplo, Lumsdaine e Papell (1997) mostram que testes que permitem a presença de duas quebras estruturais são mais poderosos do que os que permitem somente a presença de uma. Nesse sentido, Clemente, Montañés e Reyes (1998) propóem uma extensão do teste proposto por Perron e Vogelsang (1992), permitindo até duas quebras estruturais. Para o caso de quebras estruturais do tipo OA, por exemplo, é proposto um procedimento com duas etapas. Na primeira, estima-se o seguinte modelo:

$$
y_{t}=\alpha_{0}+\delta_{1} D U_{1 t}+\delta_{2} D U_{2 t}+\hat{y}_{t}
$$

Onde $D U_{m t}=1$ para $t>T_{b m}$ e 0 em caso contrário (para $m=1,2$ ). Com os resíduos da equação (9), $\hat{y}_{t}$, na segunda etapa, estima-se o seguinte modelo:

$$
\hat{y}_{t}=\sum_{t=1}^{k} \omega_{1 i} D T_{b 1, t-1}+\sum_{t=1}^{k} \omega_{2 i} D T_{b 2, t-1}+\hat{\gamma} \hat{y}_{t-1}+\sum_{t=1}^{k} \theta_{i} \Delta \hat{\alpha} \hat{y}_{t-1}+\varepsilon_{t}
$$

Onde $D T_{b m, t}=1$ para $t=T_{b m}+1 \mathrm{e} 0$ em caso contrário (para $\mathrm{m}=1,2$ ). Esta regressão é então estimada sobre os possíveis pares de $T_{1}$ e $T_{2}$, em busca do valor mínimo da razão $t$ para a hipótese nula de que $\gamma=1$. Ou seja, a hipótese nula é que a série tem uma raiz unitária contra a hipótese alternativa de que ela é estacionária com uma ou duas quebras estruturais. 
Por sua vez, o modelo OI com duas quebras é expresso da seguinte forma:

$$
\begin{gathered}
y_{t}=\alpha_{0}+\delta_{1} D U_{1 t}+\delta_{2} D U_{2 t}+\delta_{3} D T_{b 1, t}+\delta_{4} D T_{b 2, t}+\gamma y_{t-1} \\
+\sum_{t=1}^{k} \theta_{i} \Delta \hat{y}_{t-1}+\varepsilon_{t}
\end{gathered}
$$

A hipótese nula deste modelo é a mesma do modelo anterior. Os dois modelos consideram que as quebras estruturais e a ordem de defasagem $\kappa$ são desconhecidas. Os pontos de quebra são localizados por uma busca bidimensional para o valor mínimo da estatística $t$ para a hipótese de raiz unitária $(\gamma=1)$, enquanto $\kappa$ é determinada por uma série de testes sequenciais.

Uma característica desses modelos com quebras estruturais determinadas de forma endógena é que eles supóem a inexistência de quebras estruturais na hipótese nula de raiz unitária (Glynn, Perera e Verma, 2007). Lee e Strazicich (2003) mostram que esta suposição leva os testes a rejeitarem a hipótese nula e indicarem que as séries são estacionárias na presença de quebras estruturais. Assim, para corrigir este problema, propóem um teste de multiplicador de Lagrange que permite até duas quebras estruturais, as quais são consideradas em ambas as hipóteses, o que, de certa forma, restabelece as hipóteses do teste com uma quebra estrutural exógena proposto por Perron (1989). O teste permite testar tanto mudanças no intercepto (nível) quanto na tendência das séries.

No caso deste estudo, os testes de raiz unitária serão úteis para avaliar a sustentabilidade da política fiscal gaúcha seguindo-se as restriçóes propostas por Hamilton e Flavin (1986), Wilcox (1989) e Trehan e Walsh (1991), ou seja, examinar se as séries da dívida pública e do resultado primário são estacionárias ou não. Para este fim, além dos testes de raiz unitária Dickey-Fuller (1979) e Phillps-Perron (1988), serão realizados os testes de raiz unitária: com quebras estruturais endógenas, proposto por Clemente-Montañés-Reyes (1998); com quebras estruturais somente na hipótese alternativa; e com quebras estruturais em ambas as hipóteses, proposto por Lee e Strazicich (2003).

Todavia, a sustentabilidade da política fiscal não é restrita à estacionariedade de importantes indicadores de solvência fiscal, segundo Hakkio e Rush (1991) e Tanner e Liu (1994), pois, mesmo que estas sejam não estacionárias, a política pode ser sustentável se houver cointegração entre a receita tributária e a despesa primária, bem como entre a dívida pública e o resultado primário. Para avaliar a existência de cointegração, existem duas abordagens bastante conhecidas.

A primeira abordagem é uma generalização do teste $\mathrm{ADF}$ para um modelo multivariado na forma de um vetor autorregressivo (VAR), que, entre outras coisas, permite estimar um sistema de equaçóes com variáveis endógenas e suas respectivas defasagens. Este pode ser escrito como: 


$$
Y_{t}=A_{0}+A_{1} Y_{t-1}+\cdots+A_{p} Y_{t-p}+\varepsilon_{t}
$$

onde $Y$ é um vetor $n \times 1$ que inclui as séries endógenas do modelo; $A_{0}$ é um vetor de intercepto $n \times 1 ; A_{1}, \ldots, A_{p}$ são matrizes $n \times n$ de coeficientes que associam valores defasados de séries endógenas a seus valores atuais; e $\varepsilon_{t}$ é um vetor $n \times 1$ de resíduos (inovaçóes) aleatórios $I I D \sim N\left(0, \sigma^{2}\right)$. Este modelo pode ser reescrito na forma de um modelo vetorial de correção de erro (VECM) dado por:

$$
\Delta Y_{t}=\Pi Y_{t-k}+\Gamma_{1} \Delta \mathrm{Y}_{t-1}+\Gamma_{2} \Delta \mathrm{Y}_{t-2}+\cdots+\Gamma_{k-1} \Delta Y_{t-(k-1)}+\varepsilon_{t}
$$

Em que $\Pi=\left(\sum_{j-1}^{k} \beta_{i}\right)-I_{g} ; \Gamma_{i}=\left(\sum_{j-1}^{i} \beta_{j}\right)-I_{g} ; \Delta y_{t}$ é um vetor com $n$ séries, sendo $\varepsilon_{t} \sim(0, \Sigma)$, onde $\Sigma$ é uma matriz de $u_{t}$ variâncias $\operatorname{com} E\left(\varepsilon_{t} \varepsilon_{s}\right)=0, \forall t \neq s$. Tal especificação é semelhante ao teste ADF; contudo, ao invés de se testar se um coeficiente é igual a 0 , testa-se o posto da matriz П. Intuitivamente, П é uma matriz $n \times \mathrm{x} n$ cujo posto é $r \leq n$, se houver cointegração. Se o posto dessa matriz for $n$, as variáveis endógenas serão todas estacionárias. Se o posto da matriz for nulo, não existirá cointegração e as variáveis serão não estacionárias.

Para determinar o posto de П, Johansen (1988) propóe dois testes. O primeiro teste é o do traço, que assume como hipótese nula a existência de vetores de cointegraçáo contra a hipótese alternativa de $r>r_{0}$ vetores, ou seja: $H_{0}: r=r_{0} \times H_{1}: r>r_{0}$. A estatística do teste é dada por:

$$
L R\left(r_{0}, n\right)=-T \sum_{i=r_{0}+1}^{n} \ln \left(1-\hat{\lambda}_{i}\right)
$$

O teste mostra que o posto da matriz Пé igual ao número de suas raízes características diferentes de 0 . Se os autovalores obtidos forem próximos de 0 , não existirá cointegração, denotando náo estacionariedade e $\ln \left(1-\lambda_{i}\right) \rightarrow 0$. Se isso acontece, a estatística do traço resulta em valores pequenos, de tal modo que não se pode rejeitar a nula. No entanto, se $\lambda_{i}$ é significativamente diferente de 0 , então $\ln \left(1-\lambda_{i}\right)$ será negativo. A estatística terá um valor alto, e a nula será rejeitada em favor da alternativa.

O segundo teste é o de máximo autovalor, com resultados mais robustos que o anterior, mas também com distribuição não convencional. A hipótese nula desse teste é que existem $r_{0}$ vetores de cointegração; a hipótese alternativa é que existem $r_{0}+1$ vetores de cointegração: $H_{0}: r=r_{0} \times H_{1}: r=r_{0}+1$. A estatística do teste é dada por:

$$
L R\left(r_{0}, r_{0}+1\right)=-T \ln \left(1-\hat{\lambda}_{r_{0}+1}\right)
$$

Este teste verifica qual o máximo autovalor significativo que produz um vetor de cointegração. Esse autovalor máximo, correspondente ao vetor de cointegração $r_{0}$, mostra que há $r_{0}$ vetores de cointegração. Assim como o teste anterior, é um teste crescente, ou seja, rejeitar $H_{0}$ significa que há mais um vetor de cointegração. Não rejeitar $H_{0}$ significa que há $r_{0}$ vetores de cointegração. 
A segunda abordagem é a de Engle e Granger (1987), que partem do princípio de que a combinação linear de duas séries não estacionárias e integradas de mesma ordem pode ser estacionária. Nesse sentido, os autores propóem um procedimento em dois estágios. No primeiro estágio, estima-se a relação de cointegração através de uma regressão estimada por mínimos quadrados ordinários entre as séries. No segundo estágio, é realizado um teste de hipóteses baseado em um teste ADF nos resíduos desta estimação. Há cointegração quando os resíduos são estacionários, no entanto, a hipótese nula é de resíduos não estacionários e, consequentemente, ausência de cointegração; logo, há cointegração sob a aceitação da hipótese alternativa. Cabe ressaltar que a distribuição do teste é um pouco diferente de uma distribuição te se emprega uma distribuição que depende da especificação utilizada no teste ADF (sem constante, com constante, com constante e tendência).

No entanto, ambas as abordagens são semelhantes ou, na verdade, são testes $\mathrm{ADF}$ que, portanto, assumem as mesmas suposiçôes. Uma delas, conforme visto anteriormente, é a inexistência de quebras estruturais. Porém, existem poucas alternativas para se testar cointegração na presença de quebras estruturais (Giles e Godwin, 2012), e esta é uma literatura ainda em desenvolvimento. Johansen, Mosconi e Nielsen (2000) propóem uma generalização do teste do traço de Johansen (1988), considerando possíveis alterações no intercepto e na tendência do modelo estimado em períodos conhecidos. Embora os testes possuam distribuiçóes assintóticas desconhecidas, seus valores críticos podem ser obtidos seguindo os procedimentos propostos por Joyeux (2007) e Giles e Godwin (2012). A principal vantagem deste método é que a sua característica multivariada permite encontrar mais de uma relação de cointegração e a utilização de uma VAR permite lidar com o problema de endogeneidade causado por uma potencial simultaneidade entre as séries. Por sua vez, a principal limitação deste procedimento é que a quebra estrutural é exógena e os testes estão sujeitos aos mesmos problemas de datamining do teste de raiz unitária proposto por Perron (1989).

Porém, quando são testadas relações de cointegração entre somente duas séries, é possível avaliar a existência de cointegração também com modelos univariados, tal como o teste ADF nos resíduos, proposto por Engle e Granger (1987), mas com adaptaçóes para presença de quebras estruturais. Esta é a proposta do teste de Gregory e Hansen (1996), que atenuam a hipótese de invariância no tempo da relação de cointegração entre duas séries, de forma que o seu teste permite verificar se a relação de cointegração entre duas séries é válida por determinado período e também se a relaçáo de longo prazo se altera ao longo do tempo. Assim, tal como os testes de raiz unitária com quebras estruturais, o modelo permite testar a existência de cointegraçáo entre séries na presença de quebras estruturais com quatro formas funcionais distintas: modelo com mudança de nível; modelo com mudança de nível e tendência; modelo com alteração no intercepto e na inclinação; e modelo com mudança no intercepto, no coeficiente e na tendência. 
Neste estudo, ambos os testes - teste do traço modificado de Johansen, Mosconi e Nielsen (2000) e Gregory e Hansen (1996) - serão utilizados, pois os modelos teóricos de sustentabilidade da política fiscal propostos por Hakkio e Rush (1991) e Tanner e Liu (1994) sugerem avaliaçóes em pares. Serão avaliadas a cointegração entre a dívida pública e o resultado primário e a receita tributária e a despesa primária, o que, por construção, permite a existência de no máximo uma relaçáo de cointegração, que pode ser obtida tanto por meio de modelos univariados quanto multivariados.

\subsection{Base de dados}

Para a análise da política fiscal do estado do Rio Grande do Sul, são utilizadas as seguintes séries: i) Dívida Pública (DPPIB); ii) Receita Tributária (RTPIB); iii) Resultado Primário (RPPIB); e iv) Despesa Primária (DTSDPIB). Estas séries foram extraídas da Secretaria da Fazenda do Estado do Rio Grande do Sul (Sefaz RS). Além disso, trabalha-se com o PIB do estado, cujos dados foram coletados da Fundação de Economia e Estatística (FEE).

Conforme pode ser observado no gráfico 1 , as informaçóes a respeito dessas séries com periodicidade anual têm seu início em 1970, e seu término, em 2015. A receita tributária foi extraída do balanço financeiro de cada exercício; a dívida pública, do balanço patrimonial, em que é chamada de passivo permanente, e consiste na soma da dívida fundada interna com a dívida fundada externa; o resultado primário foi obtido pela subtração da receita tributária na despesa primária; ${ }^{4}$ e a despesa primária é a despesa total menos o saldo da dívida. A despesa total foi extraída da demonstração das variaçóes patrimoniais, em que é chamada de despesa orçamentária, e consiste na soma das despesas correntes e das despesas de capital. Por seu turno, o saldo da dívida é obtido pela diferença entre os juros da dívida e a amortização, tendo sido esses dados retirados da demonstração das variaçóes patrimoniais. ${ }^{5}$

4. Cabe destacar que este conceito é diferente da definição proposta pela LRF. Utiliza-se esta definição por dois motivos: i) é mais próxima da ideia de resultado primário que aparece na restrição orçamentária do governo; e ii) não se tem uma série longa do resultado primário na definição da LRF.

5. É importante ressaltar que, no ano de 2008, houve alteração na forma de contabilização das receitas e despesas do estado. Os dados passaram a ser fornecidos em um relatório resumido, fornecido bimestralmente, a partir desse ano; os valores foram extraídos do sexto bimestre de cada ano que apresenta os dados acumulados. 


\section{GRÁFICO 1}

Despesa primária (DTSDPIB), receita tributária (RTPIB), resultado primário (RPPIB) e dívida pública (DPPIB) do Rio Grande do Sul como proporção do PIB do estado (1970-2015) (Em \%)

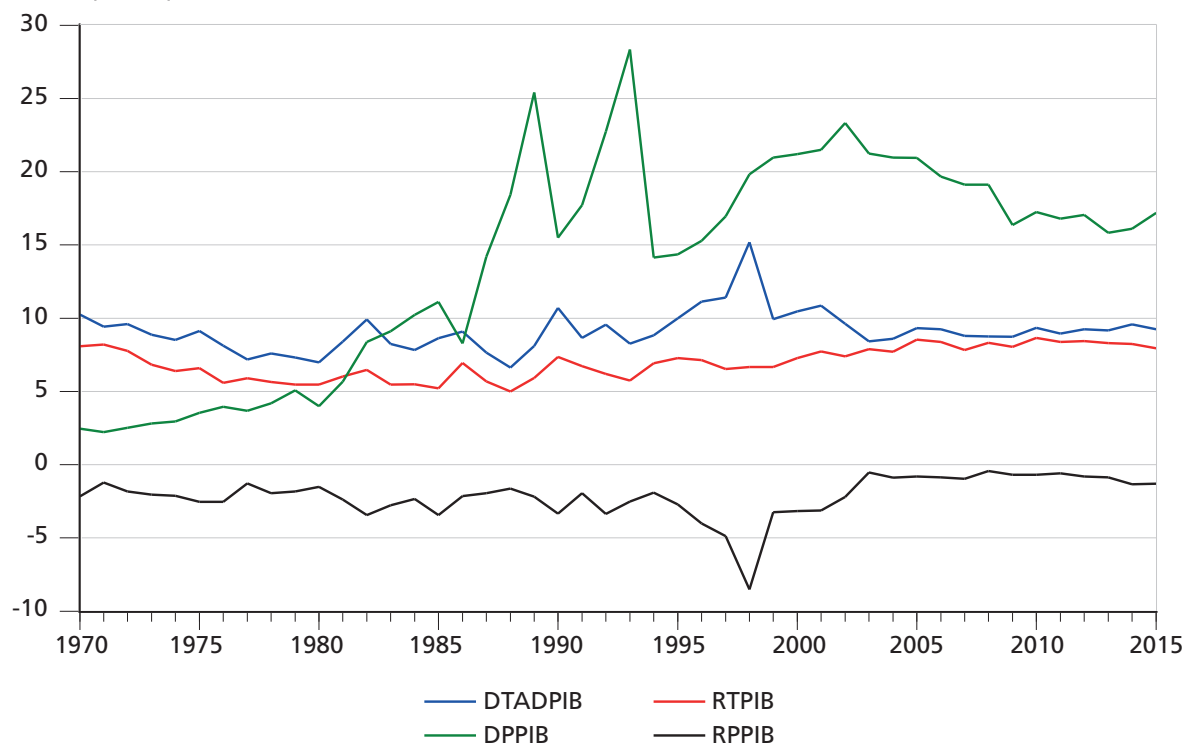

Fontes: Sefaz RS; FEE.

Conforme pode ser observado no gráfico 1, o estado do Rio Grande do Sul, desde que as informaçóes orçamentárias passaram a ser coletadas de maneira uniforme para os estados brasileiros, nunca obteve superavit primário. Logo, são quarenta e cinco anos em que o estado gasta mais do que arrecada. O resultado desta política foi o endividamento crescente, que só não é maior pelas restriçóes de financiamento impostas pela LRF. Desde a sua entrada em vigor, houve uma redução na dívida pública de cerca de $6 \%$ do PIB; no entanto, conforme pode ser visto no gráfico, esta redução não se deveu à geração de superavit primários, mas advém do crescimento do produto e da impossibilidade legal de se obterem novos financiamentos. Diante destas restriçóes, no período entre 2010 e 2014, o governo do estado passou a utilizar recursos extraorçamentários de depósitos judiciais para cumprir os gastos correntes (Santos, 2015) - recursos cuja legalidade do uso é discutível e que se esgotaram tão logo acabou o mandato do governador.

Nesse cenário adverso, desde então, o governo do estado tem tido dificuldades de cumprir os seus compromissos, e passou a realizar parcelamentos nos pagamentos tanto de fornecedores quanto de servidores. Esta aparente situação fiscal insustentável no curto prazo não necessariamente implica a insustentabilidade no longo prazo. Dessa forma, este estudo se propóe a realizar testes formais que avaliem a situaçáo no longo prazo, conforme sugere a literatura a respeito do tema. Os resultados destes testes são apresentados na próxima seção. 


\section{RESULTADOS}

Conforme comentado inicialmente para a análise da estacionariedade das séries fiscais (sustentabilidade da política fiscal), são utilizados os testes de Dickey-Fuller aumentado (ADF), Phillips-Perron (PP), Clemente-Montañés-Reyes (CMR) e Lee e Strazicich (LS). A tabela 1 apresenta os resultados para o teste ADF e PP para todas as séries avaliadas. Constata-se que, nos dois testes, há uma indicação de que a dívida pública (DPPIB) não é estacionária em nível, ou seja, aceita-se a hipótese nula de não estacionariedade. A tabela indica que o resultado primário (RPPIB) e a despesa primária (DTSDPIB) são estacionários em nível. Por sua vez, os resultados para a receita tributária (RTPIB) são contraditórios. $\mathrm{O}$ teste $\mathrm{ADF}$ indica que a série é estacionária na tendência, enquanto o teste $\mathrm{PP}$ com a mesma especificação indica que a série não é estacionária. Independentemente de possíveis contradições, os testes de raiz unitária mais tradicionais apontam para uma possível insustentabilidade da política fiscal, uma vez que a dívida pública e (possivelmente) a receita tributária são não estacionárias, e logo não atendem aos critérios de sustentabilidade da política fiscal propostos por Hakkio e Rush (1991) e Tanner e Liu (1994).

Esses resultados diferem dos estudos anteriores. Marques Junior (2005) encontrou estacionariedade tanto na série da dívida pública quanto na do resultado primário. Além disso, os valores aqui obtidos para a receita tributária e a despesa primária também diferem de Marques Junior e Jacinto (2006), que mostram que estas séries são integradas de ordem 1. Essa divergência certamente decorre da diferença entre os períodos analisados, uma vez que Marques Junior (2005) utiliza os dados de 1970 a 1997, enquanto Marques Junior e Jacinto (2006) utilizam os dados de 1970 a 2003. Ou seja, há um acréscimo de dezoito anos nas séries, desde o primeiro até este estudo.

TABELA 1

Testes de raiz unitária para a dívida pública, resultado primário, receita tributária e despesa primária do estado do Rio Grande do Sul

1 A - Dívida pública

\begin{tabular}{|c|c|c|c|c|}
\hline \multicolumn{5}{|c|}{ Teste ADF } \\
\hline \multirow{2}{*}{ Série } & \multirow{2}{*}{ p-valor assintótico } & \multicolumn{3}{|c|}{ Critérios de informação ${ }^{1}$} \\
\hline & & AIC & $\mathrm{BIC}$ & $\mathrm{HQC}$ \\
\hline Teste sem constante & 0,7158 & 217,883 & 226,451 & 221,003 \\
\hline Teste com constante & 0,3889 & 215,361 & 225,643 & 219,105 \\
\hline Com constante e tendência & 0,9162 & 217,287 & 229,282 & 221,655 \\
\hline \multicolumn{5}{|c|}{ Teste Phillips-Perron } \\
\hline \multicolumn{5}{|c|}{$Z_{t}=-1,7227(p-$ valor: 0,4132$)$} \\
\hline Coeficiente & p-valor & & & \\
\hline Constante & $0,0425^{* *}$ & & & \\
\hline DPPIB(-1) & $4,85 \mathrm{e}-038^{* * *}$ & & & \\
\hline
\end{tabular}




\section{B - Resultado primário}

\begin{tabular}{lcccc}
\hline & Teste ADF & & \\
\hline \multirow{2}{*}{ Série } & p-valor assintótico & \multicolumn{2}{c}{ Critérios de informação } \\
\cline { 3 - 5 } & & AIC & BIC & HQC \\
\hline Teste sem constante & 0,2266 & 139,133 & 142,702 & 140,456 \\
Teste com constante & 0,0368 & 138,749 & 142,362 & 140,096 \\
Com constante e tendência & 0,1055 & 139,989 & 145,409 & 142,010 \\
\hline & Teste Phillips-Perron & & & \\
\hline Coeficiente & $Z_{\mathrm{t}}=-3,0716$ (p-valor: 0,0360$)$ & & & \\
Constante & p-valor & & & \\
RPPIB(-1) & $0,0120^{* *}$ & & & \\
\hline
\end{tabular}

1C - Receita tributária

\begin{tabular}{|c|c|c|c|c|}
\hline \multicolumn{5}{|c|}{ Teste ADF } \\
\hline \multirow{2}{*}{ Série } & \multirow{2}{*}{ p-valor assintótico } & \multicolumn{3}{|c|}{ Critérios de informação } \\
\hline & & $\mathrm{AIC}$ & $\mathrm{BIC}$ & $\mathrm{HQC}$ \\
\hline Teste sem constante & 0,7751 & 77,0678 & 84,0185 & 79,615 \\
\hline Teste com constante & 0,8880 & 78,7233 & 87,4117 & 81,908 \\
\hline Com constante e tendência & 0,0019 & 58,7586 & 69,1846 & 62,580 \\
\hline \multicolumn{5}{|c|}{ Teste Phillips-Perron } \\
\hline \multicolumn{5}{|c|}{$z_{t}=-3,46356(p-$ valor: 0,0558$)$} \\
\hline Coeficiente & p-valor & & & \\
\hline Constante & $0,0020 * * *$ & & & \\
\hline Tendência & $0,0038^{* * *}$ & & & \\
\hline RTPIB(-1) & $3,24 \mathrm{e}-011^{* * *}$ & & & \\
\hline
\end{tabular}

1D - Despesa primária

\begin{tabular}{|c|c|c|c|c|}
\hline \multicolumn{5}{|c|}{ Teste ADF } \\
\hline \multirow{2}{*}{ Série } & \multirow{2}{*}{ p-valor assintótico } & \multicolumn{3}{|c|}{ Critérios de informação } \\
\hline & & AIC & $\mathrm{BIC}$ & $\mathrm{HQC}$ \\
\hline Teste sem constante & 0,5654 & 147,683 & 152,967 & 149,632 \\
\hline Teste com constante & 0,008282 & 145,845 & 149,458 & 147,192 \\
\hline Com constante e tendência & 0,02073 & 146,127 & 151,547 & 148,148 \\
\hline \multicolumn{5}{|c|}{ Teste Phillips-Perron } \\
\hline \multicolumn{5}{|c|}{$Z_{t}=-3,65755(p-$ valor: 0,0082$)$} \\
\hline Coeficiente & p-valor & & & \\
\hline Constante & $0,0003^{* * *}$ & & & \\
\hline $\operatorname{DTSDPIB}(-1)$ & $2,94 \mathrm{e}-05^{* * *}$ & & & \\
\hline
\end{tabular}

Elaboração dos autores.

Nota: ${ }^{1} \mathrm{AIC}$ - critério de informação de Akaike; BIC - critério de informação bayesiano; HQC - critério de informação de Hannan-Quinn.

Obs.: ** Significativo a $1 \%$; ** significativo a $5 \%$; e * significativo a $10 \%$. 
Todavia, estes resultados não podem ser comparados com os apresentados por Oliveira e Marques Junior (2011), uma vez que os autores não apresentam os resultados dos testes ADF, sob a justificativa de os mesmos serem viesados. Argumentam que são necessários testes que levem em conta as mudanças institucionais ocorridas no período analisado. Isto porque acreditam que a presença de quebras estruturais nas séries estudadas é motivo suficiente para alterar os resultados dos testes de raiz unitária $\mathrm{ADF}$ e PP e aceitar a hipótese nula de não estacionariedade com uma frequência maior do que a desejada. Todavia, os resultados mostrados até aqui indicam o contrário, ou seja, que não há um viés pela aceitação da hipótese nula. Porém, não se pode ignorar que o viés existe, caso existam quebras estruturais, e que tais testes não são robustos à violação da hipótese de estabilidade dos coeficientes. Para superar estas limitaçóes dos testes de raiz unitária, Oliveira e Marques Junior (2011), bem como Marques Junior e Jacinto (2006), utilizam o teste CMR. Para fins de comparação de resultados, este estudo realiza o mesmo teste, o qual permite que sejam testadas até duas quebras estruturais com duas especificações distintas, tal como descrito na seção anterior.

TABELA 2

Testes de raiz unitária com quebras estruturais de Clemente-Montañés-Reyes

\begin{tabular}{|c|c|c|c|c|c|}
\hline \multirow{2}{*}{ Variáveis } & \multicolumn{5}{|c|}{ Quebra(s) } \\
\hline & Tipo & Ano(s) & Estatistica t & Valor crítico 5\% & Estatística t (du1) \\
\hline \multirow{4}{*}{ DPPIB } & $O A$ & $1984^{* * *}$ & $-4,952$ & $-3,56$ & 11,855 \\
\hline & Ol & $1985^{* * *}$ & $-3,717$ & $-4,27$ & 3,109 \\
\hline & $\mathrm{OA}$ & $1984^{* * * / 2008}$ & $-5,267$ & $-5,49$ & 11,841 \\
\hline & Ol & $1980^{* *} / 1985^{* * *}$ & $-4,367$ & $-5,49$ & 2,251 \\
\hline \multirow{4}{*}{ RPPIB } & $\mathrm{OA}$ & 1996 & $-1,806$ & $-3,56$ & 1,069 \\
\hline & Ol & $1997^{* * *}$ & $-7,178$ & $-4,27$ & 3,833 \\
\hline & $O A$ & $1996^{* * *} / 2000^{* * *}$ & $-3,131$ & $-5,49$ & $-5,16$ \\
\hline & Ol & $1994^{* * * / 1997^{* * *}}$ & $-7,82$ & $-5,49$ & $-4,286$ \\
\hline \multirow{4}{*}{ DTSDPIB } & $\mathrm{OA}$ & $1996^{* *}$ & $-5,048$ & $-3,56$ & 2,646 \\
\hline & Ol & 1997 & $-5,803$ & $-4,27$ & 0,723 \\
\hline & $O A$ & $1995^{* * *} / 2000^{* * *}$ & $-2,063$ & $-5,49$ & 5,783 \\
\hline & Ol & $1994^{* * * / 1997^{* * *}}$ & $-7,576$ & $-5,49$ & 3,688 \\
\hline \multirow{4}{*}{ RTPIB } & $O A$ & $1997^{* * *}$ & -3.892 & $-3,56$ & 6,624 \\
\hline & Ol & $1998^{* * *}$ & $-3,013$ & $-4,27$ & 2,806 \\
\hline & OA & $1991^{* *} / 2002^{* * *}$ & $-4,424$ & $-5,49$ & 2,189 \\
\hline & Ol & $1987^{* * *} / 1998^{* * *}$ & $-5,351$ & $-5,49$ & 4,611 \\
\hline
\end{tabular}

Elaboração dos autores.

Obs.: $1 .{ }^{* * *}$ Significativo a $1 \%$; ${ }^{* *}$ significativo a $5 \%$; e * significativo a $10 \%$. 2. Testes com melhores especificações destacados em itálico. 
Conforme se observa na tabela 2, foram encontradas quebras estruturais estatisticamente significativas em todas as séries, o que justifica a necessidade de considerá-las nos testes de raiz unitária. A sua presença gera um viés que deve ser corrigido. Considerando-se os modelos que apresentaram o melhor ajustamento (coeficientes para quebras mais significativos estatisticamente, destacados em itálico), é possível observar que alguns testes apresentam resultados distintos dos apresentados nos testes ADF e PP. Por exemplo, a dívida pública, na especificação que apresenta uma quebra abrupta (OA) e significativa no ano de 1984, mostra que a dívida pública é estacionária, pois a estatística do teste $(-4,95)$ é inferior ao valor crítico para esta especificação $(-3,56)$; logo, rejeita-se a hipótese nula de não estacionariedade. Esta quebra estrutural pode ser explicada pelo aumento na dívida decorrente do aumento das taxas de juros internacionais ocasionadas pela crise do petróleo, que levou vários países e estados do Brasil endividados a terem dificuldades em administrar as suas dívidas.

Para o resultado primário, que se mostrou estacionário a 5\%, mas não a $1 \%$ nos testes anteriores, na presença de uma quebra abrupta $(\mathrm{OA})$ em dois períodos (1996 e 2000), os resultados indicam que a série é não estacionária. O mesmo ocorre com a despesa primária, que possui duas quebras abruptas (1995 e 2000), em que não se pode rejeitar a hipótese de não estacionariedade desta série. Estas quebras provavelmente refletem os efeitos de duas mudanças institucionais relevantes ocorridas no período: a renegociação da dívida mobiliária dos estados juntos à Uniāo e a promulgação da LRF em 2000. Logo, a inclusão de quebras estruturais alterou a conclusão quanto à presença de raiz unitária nestas séries.

Por sua vez, o teste para a receita tributária, que antes apresentava resultados contraditórios nos testes ADF e PP, ao incluir uma mudança abrupta no ano de 1997, mostra que se deve rejeitar a hipótese de não estacionariedade a um nível de significância de 5\%; entretanto, tal teste muda a sua interpretação, se for considerado um nível de significância de $1 \%$. Portanto, a mudança da especificação não contribuiu muito para dirimir a dúvida quanto à presença ou não de raiz unitária na série. Entretanto, vale lembrar que o teste CMR não considera a possibilidade de haver quebras estruturais na hipótese nula, o que o leva a rejeitar tal hipótese com maior frequência e assumir que as séries são estacionárias, quando na verdade não são. Tal limitação é inexistente no teste proposto por Lee e Strazicich (2003). Os resultados deste teste são apresentados na tabela 3.

Como era esperado, os resultados para o teste LS mostram algumas mudanças quando comparados com o teste CMR. A dívida pública é não estacionária quando se utiliza o teste LS. Os resultados para a série do resultado primário diferem do teste CMR, porém seguem o comportamento apresentado nos testes anteriores, ou seja, a série é estacionária utilizando um critério de $5 \%$ de significância estatística, mas não quando se considera $1 \%$. Como este estudo utiliza o critério de $5 \%$, assume-se que o resultado primário é estacionário. Entretanto, independentemente 
do teste de raiz unitária com quebra estrutural utilizado, os resultados indicam que estas séries possuem ordem de integração diferentes, o que impede que se avalie a sustentabilidade da política fiscal pela cointegração entre a dívida pública e o resultado primário.

TABELA 3

Testes do multiplicador de Lagrange de raiz unitária com quebras estruturais de Lee e Strazicich

\begin{tabular}{|c|c|c|c|c|c|c|}
\hline \multirow[b]{2}{*}{ Variáveis } & \multicolumn{6}{|c|}{ Quebra(s) } \\
\hline & Tipo & Ano(s) & Estatística t & Valor crítico $5 \%$ & $\begin{array}{c}\text { Estatística t } \\
(\mathrm{B}, \mathrm{t})\end{array}$ & Estatística $\mathrm{t}\left(\mathrm{B}_{2} \mathrm{t}\right)$ \\
\hline \multirow{3}{*}{ DPPIB } & Nível & 1997 & $-2,9702$ & $-3,487$ & 4,8360 & \\
\hline & Nível & $1981 / 1997^{* * *}$ & -3.0207 & $-3,563$ & 0,5060 & 4,8392 \\
\hline & Tendência & $1985^{* * * / 2001 * * *}$ & $-5,6094$ & $-6,185$ & 5,4321 & $-2,0030$ \\
\hline \multirow{3}{*}{ RPPIB } & Nível & 1981 & $-3,5234$ & $-3,487$ & $-1,2687$ & \\
\hline & Nível & $1991 / 2002^{* * *}$ & $-3,6546$ & $-3,563$ & $-1,1732$ & 2,1680 \\
\hline & Tendência & $1995 / 2002$ & $-6,5907$ & $-6,166$ & 0,6435 & 1,6566 \\
\hline \multirow{3}{*}{ DTSDPIB } & Nível & 1981 & $-3,5234$ & $-3,487$ & $-1,2687$ & \\
\hline & Nível & $1989^{* * * / 1991}$ & $-3,9726$ & $-3,563$ & 3,0844 & $-0,0546$ \\
\hline & Tendência & $1989^{* * * / 2004}$ & $-5,7248$ & $-6,166$ & 4,7729 & $-0,6802$ \\
\hline \multirow{3}{*}{ RTPIB } & Nível & $1984^{* * *}$ & $-1,8962$ & $-3,487$ & $-2,2385$ & \\
\hline & Nivel & $1984^{* * *} / 2002^{* * *}$ & $-2,5573$ & $-3,563$ & $-2,6858$ & 2,9398 \\
\hline & Tendência & $1980 / 2003^{* * *}$ & $-6,3973$ & $-6,185$ & 0,9553 & 5,0839 \\
\hline
\end{tabular}

Elaboração dos autores.

Obs.: $1 .{ }^{* * *}$ Significativo a $1 \%$; ${ }^{* *}$ significativo a $5 \%$; e * significativo a $10 \%$.

2. Testes com melhor especificação destacados em itálico.

Os resultados para a despesa primária corroboram o teste anterior e indicam a presença de raiz unitária nesta série, o que mostra, de certa forma, o descontrole das despesas no governo estadual. Todavia, diferentemente dos testes anteriores, não há dúvidas quanto à presença de raiz unitária na série da receita tributária. Note-se que, segundo o teste $\mathrm{CMR}$, a despesa primária era não estacionária, enquanto a receita tributária não o era. Segundo Hakkio e Rush (1991), o fato de estas séries apresentarem ordens de integração diferentes inviabiliza a sustentabilidade da política fiscal. Mas, considerando-se o teste LS, ambas são não estacionárias, o que permite à política fiscal ser sustentável, desde que as condiçóes sejam as descritas anteriormente - isto é, a regressão entre a receita tributária e o resultado primário tenha coeficiente igual a 1 e as séries sejam cointegradas (sustentabilidade forte), ou este coeficiente apresente um valor inferior a 1 e as séries sejam cointegradas (sustentabilidade fraca).

Para se testar essas hipóteses, este estudo segue os procedimentos indicados por Hakkio e Rush (1991), ou seja, segue os procedimentos de Engle e Granger (1987) para avaliar se as séries de receita tributária e despesa primária cointegram. 
No entanto, com algumas modificações. Inicialmente, avalia-se a cointegração, seguindo o procedimento de Johansen (1988), ${ }^{6}$ tal como o estudo de Afonso e Jales (2012). Como o teste não é robusto na presença de quebras estruturais, é utilizado o teste do traço proposto por Johansen, Mosconi e Nielsen (2000), cujos procedimentos são mais bem detalhados em Joyeux (2007) e Giles e Godwin (2012). Este procedimento consiste em encontrar a melhor especificação para o VAR, com resíduos normais e não autocorrelacionados e a inclusão de uma ou duas quebras estruturais definidas de forma exógena. ${ }^{7} \mathrm{O}$ modelo se ajusta com uma ou duas defasagens, com alguma vantagem para o modelo com uma defasagem, que apresenta menores critérios de informação. Para não incorrer em nenhuma arbitrariedade na escolha dos períodos em que ocorreram quebras estruturais, este estudo utiliza a indicação de períodos em que há alteração abrupta dos resíduos na estimação de um modelo recursivo. Este procedimento aponta que, nos anos de 1985 e 1998, houve alteraçóes relevantes. Assim, a tabela 4 mostra os resultados para os testes, considerando estes dois períodos separadamente e trazendo diferentes especificaçôes (com quebras estruturais no nível ou na tendência).

TABELA 4

Teste de cointegração de Johansen, Mosconi e Nielsen (2000) com quebras estruturais para a receita tributária e a despesa primária (1985 e 1998)

\begin{tabular}{crrrrr}
\hline & & \multicolumn{4}{c}{ Ano da quebra } \\
\cline { 3 - 5 } Número de defasagens & Ordem (posto) & \multicolumn{3}{c}{1985} & \multicolumn{1}{c}{1998} \\
\cline { 3 - 5 } & & \multicolumn{1}{c}{ Nível } & Tendência & Nível & Tendência \\
\cline { 3 - 5 } 2 & 0 & 12,8350 & 30,4374 & 20,6939 & 26,2453 \\
& 1 & 4,0657 & 6,5889 & 4,8594 & 5,6282 \\
Valor crítico a 10\% & 0 & 16,2222 & 22,0923 & 24,8046 & 26,8835 \\
& 1 & 4,6602 & 7,5049 & 6,4210 & 6,7853 \\
Valor crítico a 5\% & 0 & 23,65 & 33,40 & 23,81 & 34,19 \\
& 1 & 10,86 & 16,20 & 10,99 & 16,65 \\
Valor crítico a 1\% & 0 & 26,17 & 36,33 & 26,33 & 37,13 \\
& 1 & 12,68 & 18,39 & 12,79 & 18,81 \\
& 0 & 31,33 & 42,26 & 31,53 & 43,10 \\
\hline
\end{tabular}

Elaboração dos autores.

Obs.: Valores apresentados na tabela são as estatísticas do teste do traço.

Assim como os resultados para o procedimento proposto por Johansen (1988), os resultados para o procedimento de Johansen, Mosconi e Nielsen (2000) não indicam a existência de vetores cointegrantes entre as séries. Todavia, embora este

6. Estes resultados são apresentados no apêndice A. Todavia, não se encontra nenhuma relação de cointegração entre as séries para várias especificações, no teste do traço nem no do máximo autovalor.

7. Estima-se um VAR nas diferenças das séries com uma e com duas defasagens. Ambas possuem resíduos normais e não autocorrelacionados, portanto, trata-se de modelos válidos para a sua utilização no teste proposto por Johansen, Mosconi e Nielsen (2000). Os resultados destes testes são apresentados no apêndice, na tabela A.2. 
teste seja robusto em relação à existência de endogeneidade causada por simultaneidade, cabe salientar que não é muito flexível quanto a sua especificação. Dessa forma, este estudo passa a avaliar a cointegração entre as séries, utilizando os procedimentos de Engle e Granger (1987), mas considerando a possibilidade de haver quebras estruturais. Este teste, inicialmente proposto por Gregory e Hansen (1996), permite a presença de quebras estruturais que podem gerar mudança de intercepto (modelo 1), mudança de nível com tendência (modelo 2), mudança de regime com mudança de intercepto e inclinação do coeficiente (modelo 3), e mudança de regime com mudança de intercepto, coeficiente e tendência (modelo 4). Em cada especificação, deve-se escolher a estatística (ADF, Zt e Za) com o menor valor, para comparação com os valores críticos assintóticos (Gregory e Hansen, 1996).

TABELA 5

Teste de cointegração de Gregory e Hansen para a receita tributária e a despesa primária 5A - Modelo 1: mudança de nível

\begin{tabular}{lccccc}
\hline & & & \multicolumn{3}{c}{ Valores críticos assintóticos } \\
\cline { 4 - 6 } & Estatística & Quebra & $1 \%$ & $5 \%$ & $10 \%$ \\
\hline ADF & $-4,87$ & 2001 & $-5,13$ & $-4,61$ & $-4,34$ \\
Zt & $-4,48$ & 2001 & $-5,13$ & $-4,61$ & $-4,34$ \\
Za & $-28,32$ & 2001 & $-50,07$ & $-40,48$ & $-36,19$ \\
AIC & BIC & 155,93 & HQC & 152,50 \\
\hline
\end{tabular}

5B - Modelo 2: mudança de nível com tendência

\begin{tabular}{lccccc}
\hline & \multirow{2}{*}{ Estatística } & Quebra & \multicolumn{3}{c}{ Valores críticos assintóticos } \\
\cline { 4 - 6 } & & 2001 & $-5,45$ & $5 \%$ & $10 \%$ \\
\hline ADF & $-5,01$ & 2001 & $-5,45$ & $-4,99$ & $-4,72$ \\
Zt & $-4,98$ & 2001 & $-57,28$ & $-47,96$ & $-4,72$ \\
Za & $-31,49$ & BIC & 149,61 & HQC & $-43,22$ \\
AIC & 142,30 & & & & 145,04 \\
\hline
\end{tabular}

5C - Modelo 3: mudança de regime com mudança no intercepto e na inclinação do coeficiente

\begin{tabular}{lccccc}
\hline & \multirow{2}{*}{ Estatística } & Quebra & \multicolumn{3}{c}{ Valores críticos assintóticos } \\
\cline { 4 - 6 } & & & $1 \%$ & $5 \%$ & $10 \%$ \\
\hline ADF & $-4,89$ & 2000 & $-5,47$ & $-4,95$ & $-4,68$ \\
Zt & $-5,14$ & 1994 & $-5,47$ & $-4,95$ & $-4,68$ \\
Za & $-33,76$ & 1994 & $-57,17$ & $-47,04$ & $-41,85$ \\
AIC & 150,82 & BIC & 158,14 & HQC & 153,57 \\
\hline
\end{tabular}


5D - Modelo 4: mudança de regime com mudança no intercepto, no coeficiente e na tendência

\begin{tabular}{lccccc}
\hline & & & \multicolumn{3}{c}{ Valores críticos assintóticos } \\
\cline { 4 - 6 } & Estatística & Quebra & $1 \%$ & $5 \%$ & $10 \%$ \\
\hline ADF & & 1987 & $-6,02$ & $-5,5$ & $-5,24$ \\
Zt & $-5,74$ & 1993 & $-6,02$ & $-5,5$ & $-5,24$ \\
Za & $-5,77$ & 1993 & $-69,37$ & $-58,58$ & $-53,31$ \\
AIC & $-40,21$ & BIC & 170,71 & HQC & 163,85 \\
\hline
\end{tabular}

Elaboração dos autores.

Os resultados da tabela 5 indicam que, ao nível de significância de 1\%, todos os testes aceitam a hipótese nula de não cointegração; a um nível de $5 \%$, os modelos 1,2 e 3 aceitam a hipótese nula de não cointegração, enquanto o modelo 4 a rejeita. O modelo que apresenta o melhor ajustamento (menores critérios de informação) é o modelo 2 e, por esta razão, este é o modelo considerado. Este modelo apresenta todos os coeficientes significativos ao nível de $1 \%$, e os seus testes $\mathrm{Zt}$ e Za aceitam a hipótese nula de inexistência de cointegração, enquanto o teste ADF rejeita esta hipótese, porém no limite do valor crítico de $5 \%$. No entanto, cabe ressaltar que tal teste possui o mesmo problema do teste $\mathrm{CMR}$, ou seja, não inclui quebras estruturais na hipótese nula. Logo, o procedimento tende a rejeitar a hipótese nula com maior frequência. Este resultado contradiz os valores obtidos para o resultado primário. Isto ocorre porque a estacionariedade do resultado primário assume que a diferença entre a receita tributária e a despesa primária é estacionária, considerando-se um coeficiente de regressão igual a 1 , tal qual as condições necessárias para a sustentabilidade forte da política fiscal proposta por Hakkio e Rush (1991). No entanto, tal hipótese não necessariamente se verifica e, no presente caso, certamente não. Ao se estimar o modelo proposto pelos autores, ${ }^{8}$ porém, nas diferenças, pois as séries não são estacionárias, o coeficiente observado é de 0,21 , indicando que, para cada percentual do PIB de despesa criada, a receita teve um crescimento quase cinco vezes menor. Isso ilustra o total descontrole das contas públicas do governo do estado do Rio Grande do Sul nas últimas décadas.

Dessa maneira, apesar dos pontos fortes e fracos de cada teste, é possível concluir que, a partir dos testes de Johansen, Mosconi e Nielsen (2000) e de Gregory e Hansen (1996), não há uma relação de cointegração robusta entre a receita tributária e a despesa primária. Logo, não se pode afirmar que a política fiscal do estado do Rio Grande do Sul é sustentável no conceito de sustentabilidade fraca proposto por Hakkio e Rush (1991) e Tanner e Liu (1994). Além disso, é possível afirmar também que a política fiscal não é sustentável no conceito de Hamilton e Flavin (1986), Wilcox (1989) Trehan e Walsh (1991), pois a dívida pública mostrou ser uma série não estacionária.

8. Os resultados são apresentados no apêndice A, na tabela A.3. 


\section{CONCLUSÃO}

Este estudo teve por objetivo avaliar a sustentabilidade da política fiscal do estado do Rio Grande do Sul, ou seja, se a restrição orçamentária intertemporal é satisfeita no longo prazo. Ao realizar os mais variados testes de raiz unitária e cointegração, com a presença ou não de quebras estruturais, o artigo conclui que a política fiscal do estado não é sustentável. Este resultado difere dos encontrados por Marques Junior (2005), Marques Junior e Jacinto (2006) e Oliveira e Marques Junior (2011).

As razóes para essas diferenças são as seguintes: $i$ ) o tamanho da amostra, pois foram acrescentados dezoito anos em relação ao primeiro estudo; $i$ ) a diferença de metodologia, pois em nenhum dos estudos anteriores realizaram-se testes de cointegração que permitissem a presença de quebras estruturais; e iii) o fato de o período acrescentado neste estudo, em relação ao último mencionado (de 2007 a 2015), ser marcado por sérios problemas financeiros, com aumento das despesas e queda de receita a partir de 2010.

Os resultados obtidos mostram que os problemas das finanças públicas não são apenas de curto prazo, mas também de longo prazo, uma vez que a dívida pública ostenta uma trajetória insustentável, e as receitas e despesas não apresentam uma trajetória de longo prazo comum. Além de terem se verificado sistematicamente deficit primários, ao longo do tempo as despesas têm crescido a taxas superiores às receitas - uma trajetória insustentável, considerando-se os limites de endividamento impostos aos estados brasileiros pela LRF. Cabe salientar que, tal como afirmam Oliveira e Marques Junior (2011), esta "insustentabilidade” pode ser temporária, e está condicionada a possíveis mudanças do regime fiscal.

Em outras palavras, a política fiscal é insustentável se nada for mudado, mas reformas com o intuito de aumentar receitas e reduzir despesas podem ser feitas, de forma que o governo do estado seja capaz de honrar os seus compromissos. Todavia, sabe-se que não se trata de uma tarefa fácil, dada a resistência de grupos de interesse em ambos os lados da contabilidade governamental. De qualquer forma, o regime fiscal deve ser mudado para que o estado se torne solvente.

Por fim, apesar de este estudo ampliar o período em análise, a amostra dos dados ainda é muito pequena para garantir testes com alto poder (capacidade de rejeitar a hipótese nula quando esta é falsa). Em outros termos, ainda se tem uma chance relativamente alta de cometer os erros de tipo II, ou seja, aceitar que as séries são não estacionárias e que não há cointegração, quando na verdade o contrário ocorre. Infelizmente, esta é uma limitação difícil de ser superada, dado que as informaçóes a respeito das finanças estaduais têm periodicidade anual, e só começaram a ser divulgadas em 1970. Nesse caso, a superação de tais limitações passa pela busca de novas metodologias mais robustas em amostras pequenas. 


\section{REFERÊNCIAS}

AFONSO, A.; JALLES, J. T. Revisiting fiscal sustainability: panel cointegration and structural breaks in OECD countries. SSRN Electronic Journal, 2012.

CAMARERO, M.; CARRION-I-SILVESTRE, J. L.; TAMARIT, C. The relationship between debt level and fiscal sustainability in organization for economic cooperation and development countries. Economic Inquiry, v. 53, n.1, p. 129149, 2015.

CLEMENTE, J.; MONTANEÉS, A.; REYES, M. Testing for a unit root in variables with a double change in the mean. Economic Letters, v. 59, n. 2, p.175-182, 1998. CURTASU, A. R. How to Assess Public Debt Sustainability: Empirical Evidence for the Advanced European Countries. Romanian Journal of Fiscal Policy, v. 2, n. 2, p.20-43, 2011.

DICKEY, D. A.; FULLER, W. A. Distribution of the estimators for autoregressive time series with a unit root. Journal of the American Statistical Association, v. 74, n. 366, p.427-431, 1979.

ENGLE, R. F.; GRANGER, C. W. J. Cointegration and error correction: representation, estimation, and testing. Econometrica, v. 55, n. 2, p.251-76, 1987.

GILES, D. E.; GODWIN, R. T. Testing for multivariate cointegration in the presence of structural breaks: $p$-values and critical values. Applied Economics Letters, v. 19, n.16, p. 1561-1565, 2012.

GLYNN, J.; PERERA, N.; VERMA, R. Unit root tests and structural breaks: a survey with applications - contrastes de raíces unitarias y cambios estructurales: un estudio con aplicaciones. Revista de Métodos Cuantitativos para la Economía y la Empresa, v. 3, n. 0, p. 63-79, 2007.

GREGORY, A. W.; HANSEN, B. E. Residual-based tests for cointegration in models with regime shifts. Journal of Econometrics, v. 70, n. 1, p.99-126, 1996. HAKKIO, C. S.; RUSH, M. Is the budget deficit "Too Large"? Economic Inquiry, v. 29, n. 3, p.429-445, 1991.

HAMILTON, J. D.; FLAVIN, M. A. On the limitations of government borrowing: a framework for empirical testing. The American Economic Review, v. 76, n. 4, p.808-819, 1986.

JOHANSEN, S. Statistical analysis of cointegration vectors. Journal of Economic Dynamics and Control, v. 12, n. 2, p. 231-254, 1988.

JOHANSEN, S.; MOSCONI, R.; NIELSEN, B. Cointegration analysis in the presence of structural breaks in the deterministic trend. Econometrics Journal, v. 3, n.2, p. 216-249, 2000. 
JOYEUX, R. How to deal with structural breaks in practical cointegration analysis? In: RAO, B. B. (Ed.). Cointegration for the applied economist. New York: Second Ed. Palgrave Macmillan, p.195-221, 2007.

LEE, J.; STRAZICICH, M. C. Minimum Lagrange multiplier unit root test with two structural breaks. The Review of Economics and Statistics, v. 85, n.4, p. 1082-1089, 2003.

LUMSDAINE, R. L.; PAPELL, D. H. Multiple trend breaks and the unit-root hypothesis. The Review of Economics and Statistics, v. 79, n.2, p. 212-218, 1997.

MARQUES JUNIOR, L. S. A sustentabilidade da política fiscal do RS (19701997). Ensaios FEE, n. 26, p.249-270, 2005.

- A dívida pública do RS e a proposta de se recriar dívida estadual junto aos bancos privados. Ensaios FEE, Porto Alegre, n. 34, p.955-982, 2013.

MARQUES JUNIOR, L. S.; JACINTO, P. A. Uma retomada da discussão sobre a sustentabilidade da política fiscal do Rio Grande do Sul. Nova Economia,v. 21, n. 2, p.263-280, 2006.

NDORICIMPA, A. Structural breaks and fiscal deficit sustainability in EAC countries: Empirical Evidence. Finance and Management Sciences, v. 1, n. 6, p.391-399, 2013.

OLIVEIRA, C. A.; MARQUES JUNIOR, L. S. Dinâmica de transição e sustentabilidade da política fiscal no Rio Grande do Sul. Economia, v. 12, n. 3, p. 581-607, 2011.

PERRON, P. The great crash, the oil price shock, and the unit root hypothesis. Econometrica, v. 57, n.6, p. 1361-1401, 1989.

. Further evidence on breaking trend functions in macroeconomic variables. Journal of Econometrics, v. 80, n. 2, p. 355-385, 1997.

PERRON, P.; VOGELSANG, T. J. Testing for a unit root in a time series with a changing mean: corrections and extensions. Journal of Business \& Economic Statistics, v. 10, n.4, p. 467-470, 1992.

PHILLIPS, P.; PERRON, P. Testing for a unit root in time series regression. Biometrika, v. 75, n. 2, p.335-346, 1988.

SANTOS, D. F. Estados brasileiros em 15 anos da Lei de Responsabilidade Fiscal - LRF. Porto Alegre: AGE, 2015. Disponível em: <https://bit.ly/2DnMTpX>. Acesso em: 1 set. 2018

TANNER, E.; LIU, P. Is the budget deficit too large? Some further evidence. Economic Inquiry, v. 32, n. 3, p.511-518, 1994. 
TREHAN, B.; WALSH, C. E. Testing intertemporal budget constraints: theory and applications to U.S. federal budget and current account deficits. Journal of Money, Credit, and Banking, v. 23, n. 2, p.206-223, 1991.

WILCOX, D. The sustainability of government deficits: implications of the present-value borrowing constraint. Journal of Money, Credit and Banking, v. 21, p.291-306, 1989. 


\section{APÊNDICE A}

TABELA A. 1

Teste de cointegração de Johansen sem quebras estruturais para as séries receita tributária e despesa primária

\begin{tabular}{cccccc}
\hline Número de defasagens & Ordem (posto) & Teste traço & p-valor & Teste Lmax & $p$-valor \\
\hline \multirow{2}{*}{6} & 0 & 9,1768 & 0,3558 & 6,9203 & 0,5070 \\
& 1 & 2,2566 & 0,1330 & 2,2566 & 0,1330 \\
5 & 0 & 11,7720 & 0,1702 & 10,7630 & 0,1690 \\
& 1 & 1,0098 & 0,3150 & 1,0098 & 0,3150 \\
4 & 0 & 8,1189 & 0,4601 & 7,5968 & 0,4300 \\
\multirow{2}{*}{3} & 1 & 0,5220 & 0,4700 & 0,5220 & 0,4700 \\
& 0 & 7,8282 & 0,4911 & 5,8903 & 0,6328 \\
2 & 1 & 1,9379 & 0,1639 & 1,9379 & 0,1639 \\
& 0 & 10,8450 & 0,2250 & 7,7024 & 0,4185 \\
& 1 & 3,1423 & 0,0763 & 3,1423 & 0,0763 \\
& 0 & 15,9600 & 0,0409 & 12,3470 & 0,0980 \\
\hline
\end{tabular}

Elaboração dos autores.

TABELA A. 2

Testes de autocorrelação e de normalidade dos resíduos, e critérios de informação do VAR

\begin{tabular}{|c|c|c|c|c|c|c|c|c|}
\hline \multirow[b]{3}{*}{ Lag } & \multicolumn{7}{|c|}{ VAR (1) } & $\operatorname{VAR}(2)$ \\
\hline & \multicolumn{2}{|c|}{ Receita tributária } & \multicolumn{2}{|c|}{ Despesa primária } & \multicolumn{2}{|c|}{ Receita tributária } & \multicolumn{2}{|c|}{ Despesa primária } \\
\hline & Rao F & Prob. & Rao F & Prob. & Rao F & Prob. & Rao F & Prob. \\
\hline 1 & 0,3556 & 0,8393 & 0,3556 & 0,8393 & 0,3362 & 0,8526 & 0,3362 & 0,8526 \\
\hline 2 & 1,3011 & 0,2781 & 1,0448 & 0,4123 & 0,5630 & 0,6903 & 0,3941 & 0,9195 \\
\hline 3 & 1,8306 & 0,1326 & 1,4511 & 0,1678 & 1,2965 & 0,2808 & 0,9438 & 0,5115 \\
\hline 4 & 1,0832 & 0,3715 & 1,0841 & 0,3904 & 0,2437 & 0,9124 & 0,6721 & 0,8072 \\
\hline Jarque-Bera & 0,8554 & 0,6520 & 0,6299 & 0,7298 & 0,7365 & 0,6919 & 1,2260 & 0,5417 \\
\hline Doornik-Hansen & 1,4854 & 0,8292 & & & 1,9626 & 0,7426 & & \\
\hline $\mathrm{AIC}$ & 4,2735 & & & & 4,3359 & & & \\
\hline $\mathrm{BIC}$ & 4,7602 & & & & 4,9913 & & & \\
\hline
\end{tabular}

Elaboração dos autores.

Obs.: Séries nas primeiras diferenças. Teste de Doornik-Hansen e critérios de informação referentes ao conjunto dos modelos. 
TABELA A.3

Relação de curto prazo entre a receita tributária e a despesa primária do estado do Rio Grande do Sul (1970-2015)

\begin{tabular}{lrccc}
\hline & \multicolumn{4}{c}{ Variável dependente: receita tributária } \\
\cline { 2 - 5 } & Coeficiente & Erro-padrão & razão-t & p-valor \\
\hline Constante & 0,0017 & 0,0853 & 0,019 & 0,9842 \\
Despesa primária & 0,2132 & 0,0637 & 3,346 & 0,0017 \\
$R^{2}$ & 0,206569 & & $R^{2}$ ajustado & 0,188117 \\
$F(1,43)$ & 11,19502 & P-valor(F) & 0,001710 \\
rô & $-0,150232$ & Durbin-Watson & 2,289721 \\
\hline
\end{tabular}

Elaboração dos autores.

Obs.: Séries nas primeiras diferenças. Estimação por mínimos quadrados ordinários.

Data da submissão: 1/9/2017

Primeira decisão editorial em: 17/7/2018

Última versão recebida em: 2/9/2018

Aprovação final em: 14/9/2018 
